\title{
El declive del negocio de los Servicios de Tarificación Adicional en la televisión en España ${ }^{1}$
}

\section{The decline of the business of premium rate services in Spanish TV}

\author{
Jorge Clemente Mediavilla. Universidad Complutense de Madrid \\ Javier Domínguez Martínez. Universidad Complutense de Madrid
}

Recibido: 6-3-2013 - Aceptado: 2-5-2013

Resumen:

Durante más de una década, las televisiones españolas han venido ofreciendo con intensidad todo tipo de servicios adquiribles a través del teléfono móvil, mediante el envío de SMS Premium o la realización de llamadas de valor añadido. Sin embargo, la comercialización de estos servicios se ha reducido muy intensamente, a raíz de importantes novedades legislativas, algunas de las cuales regulan específicamente el sector de los Servicios de Tarificación Adicional (STA). El presente trabajo analiza con detalle los cambios legislativos ocurridos en nuestro país como causa principal del declive del negocio, señalándose también otras razones influyentes, todo ello a través de un profundo análisis de contenido, tanto de programas de televisión como de textos legales relacionados con el objeto de estudio.

Palabras clave:

Televisión; Interactividad; Servicios de Tarificación Adicional; SMS Premium; Legislación española.

Abstract:

For more than a decade now, Spanish television networks have been offering all kinds of services purchables with mobile telephones, by sending SMS Premium messages or making a Premium Rate telephone call. However, the marketing of these services has decreased significantly. In the decline of this business, a major role has been played by the appearance of important new legislation, which was written specifically with the aim of regulating the sector of Premium Rate Services (PRS). This paper presents a detailed analysis of the modification of laws as the main cause for that decline, and it also offers an account of other factors which have also contributed to the process, in a deep content analysis, of TV programmes and legal texts.

Key words:

Television; Interactivity; Premium Rates Services; SMS Premium; Spanish Regulation.

1 El presente trabajo es fruto de la investigación titulada "Nuevos negocios en televisión: Fundamentos del Fenómeno de los Servicios de Tarificación Adicional a través de SMS Premium y Llamadas de Valor Añadido en la Televisión en España”, financiada a través del programa de Formación del Profesorado Universitario del Ministerio de Educación (2009-2012). 


\section{Estado de la cuestión}

La llegada de la Televisión Digital Terrestre supuso la gestación de un nuevo panorama televisivo, cuya materialización más destacada fue el aumento del número de canales, algo que ha ocasionado la fragmentación de las audiencias, un fenómeno con negativas consecuencias respecto a la tradicional forma de financiación de las televisiones, la venta de espacios publicitarios, que resultan muchos más baratos para los anunciantes que antes. A ello hay que añadir un segundo motivo de preocupación para las cuentas de las empresas televisivas: la caída de la inversión publicitaria en televisión, motivada por la inversión en nuevos medios, así como por el descenso generalizado de la misma, como resultado de la crisis económica mundial que se inició en 2008.

Este alertador discurso da apertura al último informe anual de Infoadex, la entidad encargada de medir la inversión publicitaria en los medios, de tal forma que en el mismo texto de presentación de dicho Estudio Infoadex de la inversión publicitaria en España 2012 su presidente, Miguel Ángel Sánchez, expresa que "la Inversión Publicitaria en España presenta una tasa de crecimiento negativo del 6,5\% en el año 2011 para el total del mercado", dato que "representa la continuación de la tendencia negativa que comenzó en el año 2008” (http://www.infoadex.es/Resumen_Estudio_Inversiones_InfoAdex_2012.pdf).

Idéntica idea es protagonista en el más reciente Informe económico sectorial de la Comisión del Mercado de las Telecomunicaciones, relativo al año 2011, pues ya en la Carta del Presidente (Bernardo Lorenzo), este explica que "la actividad en el sector audiovisual se ha visto afectada por la crisis económica", que se evidencia por "una bajada interanual del 6,7\%" que "tuvo su origen en la disminución de los ingresos publicitarios" (http://informecmt.cmt.es).

Puestas así las cosas, no es de extrañar que los gestores de las televisiones hayan tratado de compensar esta realidad a través de otros caudales de dinero, distintos a la venta de espacios publicitarios, siendo uno de los mejores el que emana de un supuesto ofrecimiento de interactividad a la audiencia, si bien ello resulta en la conversión del espectador televisivo en cliente, ya que a tal fin es necesaria la existencia de un uso telefónico.

Esta fue la idea principal del VII Foro Audiovisual organizado por el Instituto de Empresa (IE Business School Executive Education), titulado La interactividad como fuente de ingresos alternativa en el nuevo entorno televisivo y celebrado en Madrid en mayo de 2009, año en el que precisamente se produjeron los primeros movimientos depresivos en los datos económicos de las cadenas de televisión como consecuencia de los mencionados fenómenos². Un excelente ejemplo de ello es el de Telecinco, toda vez que en 2009 dejó de ser la cadena más vista tras cinco años de liderazgo y cerró dicho ejercicio con

2 Datos obtenidos de www.execed.ie.edu/openprograms/ProgramasAbiertosDetalle.aspx?id=1055 (Dirección web del IE Business School, que contiene la información del VII Foro Audiovisual). 
un beneficio de 48,4 millones de euros, un resultado un 77\% inferior al del año anterior, con una reducción del 33,2\% de sus ingresos totales netos de explotación ${ }^{3}$.

Precisamente, el máximo representante de esta emisora de televisión en el mencionado evento, Chema Bautista, Director de Nuevos Negocios de Telecinco, nos cuenta que «en estos momentos de crisis con caídas del 30\% en los ingresos convencionales cualquier actividad que pueda ayudar a compensar es bien recibida».

En consecuencia, la telefonía ha supuesto un consuelo para las televisiones, teniendo en cuenta que los Servicios de Tarificación Adicional (STA) (a través de SMS Premium y Llamadas de Valor Añadido) han proporcionado a las emisoras de televisión importantísimos ingresos, un cuantioso reporte adicional que en verdad se inició mucho tiempo antes de que comenzaran esos dos inconvenientes característicos de la etapa digital. Sin embargo, los ingresos procedentes del consumo telefónico de los espectadores de televisión se han reducido de un modo vertiginoso.

Los datos más recientes del grupo de televisión con mayor cuota de audiencia televisiva (Mediaset España) sirven como demostración de dicho descenso. Así, en su último Hecho Relevante comunicado a la Comisión Nacional del Mercado deValores (CNMV) (correspondiente a los resultados obtenidos en los nueve primeros meses de 2012), Mediaset España advierte que sus "Otros ingresos", entre los que se incluyen los ingresos por "SMS, Call TVy de servicios de audiotex", se sitúan en 34,90 millones de euros, cifra inferior a la registrada en el mismo período de 2011, que fue de 43,79 millones de euros, empeoramiento que explica como una consecuencia de la caída de ingresos procedentes de SMS y teléfono, y que también se entiende allí como un reflejo de la situación de la economía española, que ha reducido el consumo en este tipo de productos ${ }^{4}$.

La opinión del directivo de Mediaset mencionado anteriormente coincide con la argumentación de Mediaset España en dicha comunicación, al señalar aquel que "se está viviendo un momento de impasse que se explica fundamentalmente por la crisis en el bolsillo del consumidor".

En definitiva, aunque la cantidad de dinero procedente del negocio de los Servicios de Tarificación Adicional no es nada despreciable, también resulta muy considerable el porcentaje de descenso de dicha cifra con respecto ya no de las cifras astronómicas que se generaban años atrás, sino simplemente de los datos inmediatamente anteriores, los del mismo período de 2011 (un 20,31\% menos).

Una percepción más completa de esta evolución negativa se obtiene atendiendo a los datos totales de los periódicos informes anuales del estudio de Infoadex Inversión real estimada de los anunciantes de mensajes a móviles en las diferentes

3 Datos obtenidos de www.mediaset.es/inversores/es/Informe_MDSFIL20111227_0031.pdf (Dirección de la web de Mediaset España de información a inversores, que contiene el Informe Anual de la empresa -Gestevisión Telecinco S.A.-, relativo al año 2009).

4 Datos obtenidos de http://www.mediaset.es/inversores/es/SPANISH-CNMV_MDSFIL20121024_0002.pdf (Dirección de la web de Mediaset España de información a inversores, que contiene el Informe de Resultados Enero - Septiembre 2012 de la empresa). 
cadenas de televisión. Por ejemplo, en solo dos años desde que se iniciara la complicación de la situación macroeconómica dicha inversión se ve reducida a la cuarta parte, puesto que en 2008, año en que se alcanza la máxima cifra, el total general ascendía a 76 millones de euros y en 2010 esta es ya solamente de 18 millones de euros 5 .

\section{Hipótesis y Objetivos}

A pesar de todo lo anterior, y siendo que la actividad mencionada ha sufrido una importante caída coincidiendo con el período de regulación en nuestro país de los Servicios de Tarificación Adicional, establecemos como primera hipótesis que dicho revés se debe en mayor medida al referido proceso regulador $(\mathbf{H} \mathbf{1})$.

La formulación de la anterior hipótesis implica la atribución de una importancia superior al factor legislativo, lo que puede resultar contradictorio, toda vez que nuestro planteamiento inicial versó sobre la realidad económica en el sector empresarial televisivo.

Sin embargo, al margen de interpretaciones sobre cuál es la esencia de la norma jurídica, lo que no admite discusión es su capacidad sancionadora y prescriptiva, que se presenta como característica ineludible.

Los autores de Mobile MK: La revolución multimedia expresan de una manera muy explícita la importancia clave de la dimensión legal, al señalar que:

«Un aspecto clave que es necesario conocer a la hora de utilizar el móvil como herramienta de marketing interactivo es el cumplimiento de los requerimientos legales» (Román et al., 2005).

En otras palabras, aunque las leyes traten de ser valiosas, no tienen siempre la misma relación con la realidad (a veces, se anticipan a una determinada realidad y, otras veces, van por detrás de aquella).

En todo caso, esto que decimos no resulta incompatible con la idea de que el contexto tiene una gran influencia, lo que nos conduce a formular una segunda hipótesis, una vez evaluamos el sentido y significado del objeto de estudio sometido a examen (hablamos de una actividad económica expuesta en los medios de comunicación). Consecuentemente, establecemos en la realidad económica -porque la recesión que atraviesa nuestro país conlleva la reducción del consumo-y en la percepción social -porque la consideración negativa de los STA (desconfianza, percepción de banalidad...) reduce su consumo, máxime en un contexto de desaceleración económica- los siguientes motivos con influencia en la contracción del negocio (H2).

5 Datos obtenidos del estudio de Infoadex “Inversión real estimada de los anunciantes de mensajes a móviles en las diferentes cadenas de televisión".

60 | n 17, pp. 57-77 | doxa.comunicación 
En virtud de dichas hipótesis, se hace ineludible analizar la influencia que ha tenido la aparición de los distintos textos legales en el agotamiento del negocio de los STA. El análisis de esta cuestión es, de hecho, el objetivo principal en estas páginas.

Determinar la influencia de los demás factores de contexto que ofrecen dicha posibilidad, por cuanto que hablamos de un negocio, se convierte en el segundo propósito de esta investigación.

\section{Metodología}

Desde un punto de vista metodológico, para la consecución del estudio que presentamos se ha desarrollado una exhaustiva recopilación documental, tanto textual -a través de documentos escritos y electrónicos producidos en el ámbito nacional- como audiovisual -visionando múltiples horas de emisión de programas de televisión en los que son publicitados los distintos Servicios de Tarificación Adicional-, con el fin de obtener la información requerida para llevar a cabo este análisis del proceso de declive del negocio de los Servicios de Tarificación Adicional en la televisión en España.

Concretamente, y en congruencia con la importancia que hemos atribuido en el punto anterior a los distintos textos legales para explicar el declive del negocio, debemos puntualizar que se ha revisado toda la normativa existente en nuestro país que afecta a la realidad examinada en este estudio.

Posteriormente, con los resultados obtenidos se ha realizado un profundo análisis de contenido, que nos ha permitido llegar a una serie de conclusiones acerca del tema de investigación planteado.

\section{Resultados}

\subsection{Influencia de la regulación}

El estudio de la regulación de los Servicios de Tarificación Adicional (STA) nos permitirá entender su influencia en el proceso de declive del negocio que ha supuesto, para las televisiones, la venta de dichos servicios en los bloques de publicidad y en los propios programas.

Así, el comienzo de dicho proceso se inicia con la aparición de la Resolución de 4 de diciembre de 2008, que tuvo una influencia negativa muy notable en el consumo a través de la vía telefónica del negocio consistente en la realización de llamadas de valor añadido, fuente fundamental de ingresos en algunos de los productos o servicios de mayor éxito o con mayor recaudación de dicho negocio, como los concursos telefónicos (a veces, como forma de acceso al servicio ofrecida en conjunción con la vía telefónica basada en el envío de mensajes SMS y como elemento secundario del programa, como son los “Concursos SMS - 905", y en otras ocasiones ofertada de manera única y como elemento protagonista del mismo 
(como en el formato televisivo de Call TV o las votaciones telefónicas, que en algunos formatos televisivos, como el reality show, suponen un elemento vital, incluso con consecuencias en la propia narrativa audiovisual.

Dicha Resolución atribuyó el código 905 (a través del que se ofrecen por dicha vía telefónica la gran mayoría de productos y servicios del negocio) a la prestación de los STA basados en el tratamiento de llamadas masivas y estableció importantes medidas de control. Es de ver, entre otras, la obligación de incluir locuciones informativas sobre precios y otros datos del servicio, con un evidente efecto disuasivo de la participación, así como la determinación del derecho de los usuarios a la desconexión de dicho prefijo telefónico, una posibilidad que además comportó el bloqueo automático de dichos números a aquellos usuarios que ya habían sido desconectados de los otros códigos telefónicos de tarificación adicional (como el 806 y el 803, a través de los que se ofrecen los servicios de tarot y cartomancia o eróticos, respectivamente).

La publicación del Código de Conducta de 29 de junio de 2009, para la prestación de los STA basados en el envío de mensajes SMS Premium, tuvo una repercusión muy importante en la otra vía telefónica de ingresos del negocio, que se produce mediante el envío de mensajes SMS, tal y como describe el propio título del texto legal, y que es la forma de acceso fundamental en productos o servicios del negocio como los contenidos para móvil (imágenes, música, vídeos), tanto en la modalidad de "Servicios Bajo Demanda" como en la modalidad de "Servicios de Suscripción”, o los SMS-Opinión.

Este texto legal, que quedaría consolidado el 17 de junio de 2010 tras diversas modificaciones, también tuvo un impactante efecto atenuador del negocio, cuando a raíz del mismo se obligó a que en la publicidad de los servicios, así como en los mensajes en que se materializa el ofrecimiento del servicio, se ofreciera mayor y más legible información (acerca del precio, de la empresa responsable...). También, este Código de Conducta establece normas para la especial protección de los menores, concernientes a los horarios de la publicidad y el funcionamiento de servicios dirigidos tanto a menores como a adultos. En adición a lo anterior, en dicho texto se recogen las condiciones específicas para los STA ofrecidos a través de SMS Premium que suponen concursos o votaciones (estas acciones deben contar con unas bases legales depositadas ante notario y los mensajes recibidos fuera del período de vigencia de la acción no tendrán tarificación adicional). Por último, son especialmente significativas las medidas impuestas en relación con los servicios de suscripción (la contratación se realizará únicamente después de que el usuario envíe la palabra "ALTA" y bastará para que sea cancelada que el usuario envíe la palabra "BAJA"), que evitaron desde entonces un gran porcentaje de contrataciones indeseadas por parte de aquellos usuarios desconocedores del funcionamiento de estos servicios.

Por otro lado, la Resolución de 8 de julio de 2009, que modifica el Código de Conducta para la prestación de los STA de fecha 23 de julio de 2004, originó una nueva trascendencia para los productos y servicios de voz (ofrecidos con la realización de una llamada de valor añadido), al establecer, entre otros aspectos, condiciones complementarias para la publicidad de los servicios (el precio y el prestador del servicio deben figurar en caracteres estáticos) y nuevas imposiciones en relación con la mencionada locución informativa sobre precios y otros datos del servicio (debe tener una duración mínima de once 
segundos, por lo que el usuario ha de esperar un tiempo mínimo para realizar cada llamada, tiempo en que si se interrumpiera la llamada únicamente se facturaría el servicio de soporte telefónico). Esta Resolución también obliga a indicar en la pantalla, durante la emisión de concursos que propicien las llamadas de los usuarios, un rótulo informativo del número de llamadas recibidas en los últimos diez minutos.

Otros textos legales también han influido de una manera adyacente en el declive de este negocio de las televisiones. En este sentido, es especialmente destacable la Ley 7/2010, de 31 de marzo, General de la Comunicación Audiovisual, que establece condiciones en su Artículo 7, de "Los derechos del menor", para los productos o servicios más ofertados por las televisiones al espectador en relación con dicho negocio de los STA (esto es, aquellos que materializan su recaudación con la emisión de espacios enteros de interactividad telefónica). Concretamente, dicho texto legal introduce una restricción en el horario de emisión televisiva de los espacios de futurología (tarot y cartomancia) y de los concursos telefónicos y delimita una responsabilidad subsidiaria en la empresa televisiva ante los fraudes de dichos espacios:

«Los programas dedicados a juegos de azar y apuestas, solo pueden emitirse entre la una y las cinco de la mañana. Aquellos con contenido relacionado con el esoterismo y las paraciencias, solo podrán emitirse entre las 22 y las 7 de la mañana. En todo caso, los prestadores del servicio de comunicación audiovisual tendrán responsabilidad subsidiaria sobre los fraudes que se puedan producir a través de estos programas» (Ley 7/2010, de 31 de marzo, General de la Comunicación Audiovisual).

Esta limitación de la presencia televisiva de ambos tipos de emisiones con su relegación al horario de madrugada provocó la desaparición paulatina de los concursos telefónicos en todas las parrillas televisivas, aunque serían sustituidos por otros espacios cuyo reporte para la cadena se produce igualmente convirtiendo al espectador en cliente (fundamentalmente, espacios esotéricos y teletienda). En el mismo mes de la entrada en vigor de la Ley General Audiovisual desaparecieron casi la totalidad de los programas Call TVque se emitían en ese momento (tanto en el horario prohibido como en el nuevo horario permitido).

Otro texto legal de especial consideración en este análisis, también en colisión marginal con el negocio, es la Ley 13/2011 de 27 de mayo, de regulación del juego, y ello en lo relativo a los productos y servicios que prefiguran la existencia de una actividad de juego. Pero dicha Ley no se puso en práctica hasta el 1 de junio de 2012, fecha en que la Dirección General de Ordenación del Juego dictó unas muy esperadas resoluciones con relación a las solicitudes de licencia de operador de juego y se otorgaron, por tanto, los "permisos" para el desarrollo y explotación de actividades de juego de ámbito estatal. Entonces, muchas entidades tuvieron que dejar de organizar actividades de juego. Un buen ejemplo de ello lo encontramos en los mencionados concursos de interactividad telefónica (Call TV), ya que aquellos que aún permanecían en emisión de manera regular durante 2012 desaparecieron cuando se acercaba la fecha en que el Ministerio tomaría su decisión (la entidad organizadora de "Adivina quién gana esta noche", de Antena 3, y que finalizó sus emisiones el lunes 14 de mayo de 2012, era una empresa llamada Llama Televisión S.L., que no solicitó una licencia de operador de juego y la entidad or- 
ganizadora de "Locos por Ganar", emitido en Telecinco, y que finalizó sus emisiones el jueves 31 de mayo de 2012, la víspera del día en que se concedieron las licencias, era Mediageneris S.L., quien tampoco solicitó dicha licencia). En todo caso, pese a que algunos grupos de comunicación obtuvieron licencia de operadores de juego, el panorama actual es de ausencia de este tipo de programas de interactividad telefónica.

De dicha Ley deviene una Orden de desarrollo, la Orden EHA/3084/2011, de 8 de noviembre, por la que se aprueba la reglamentación básica de los concursos, que asienta todas las condiciones a cumplir en este tipo de celebraciones. Es una excelente demostración del carácter prescriptor de la legislación el último artículo de esta Orden, que impide que la cuantía de los premios de un concurso sea superior a un millón de euros, siendo que lo habitual hace unos años era la concurrencia de celebraciones cuyos premios superaban, por mucho, dicha cantidad.

Mención aparte merece la Ley 8/2009, de 28 de agosto, de financiación de la Corporación de Radio y Televisión Española, que desde el 1 de enero de 2010 impide la emisión de publicidad en la televisión pública de ámbito estatal y que, en consecuencia, ha ocasionado también la cancelación de la celebración de acciones publicitarias encaminadas a la recaudación a través de la oferta de STA, en los medios gestionados por dicho organismo público, algo habitual hasta entonces. Por el contrario, la recurrencia a los STA desde esa fecha únicamente se produce en la forma de votaciones, para canalizar la opinión de los espectadores de la televisión pública en decisiones que, o bien se consideran de "interés cultural nacional" (la elección del representante español en Eurovisión o el reparto numérico de puntos de España en el mencionado festival de la canción), o bien son considerados de tal modo por este ente, como ocurre en otras acciones consideradas votaciones sobre realidades de interés histórico nacional pero que desde un punto de vista publicitario se formulan más razonablemente como juegos telefónicos, promocionados en el canal público por el operador de juego Eurojuego Star.

La noticia “El Sueño Olímpico de TVE, más premios en metálico que medallas", publicada en la web del diario El Mundo en este sentido expresa:

«Los espectadores votan a su juicio el episodio cumbre del olimpismo, formalismo inevitable según la normativa audiovisual, pero los participantes no aspiran sino a alcanzar premios» (El Mundo, 2 de agosto de 2012).

La noticia incluye también el punto de vista de la empresa organizadora del evento, Eurojuego Star, quien defiende la naturaleza no publicitaria de dicho espacio, al exponer que la Ley que analizamos, que elimina la publicidad como forma de financiación de la Corporación, indica que:

6 Datos obtenidos de http://www.elmundo.es/elmundo/2012/08/02/television/1343906773.html (Dirección web del diario El Mundo, que contiene el artículo “'El Sueño Olímpico de TVE', más premios en metálico que medallas”). 
«No pueden considerarse contenidos publicitarios aquellos en los que se requiere la participación de los espectadores en programas que forman parte del desarrollo propio del formato, tal como ocurre en Sueño Olímpico» (El Mundo, 2 de agosto de 2012).

Eventos legales más recientes, también achacables a este proceso o fenómeno de decadencia, son las decisiones impositivas de los últimos dos Gobiernos españoles, al disponer como medida contra la crisis económica dos subidas del Impuesto sobre el Valor Añadido (IVA). La subida impositiva ocurrida en 2010, durante la segunda legislatura de José Luis Rodríguez Zapatero, que incrementó el tipo impositivo de los SMS Premium y las Llamadas de Valor Añadido de un 16\% a un 18\%, no tuvo tan negativa repercusión como la acaecida en 2012, durante el Gobierno de Mariano Rajoy, que lo elevó de un 18\% a un $21 \%$, por cuanto que la primera subida impositiva-también menos significativa (de dos puntos)-se produjo unos meses después de un descenso en los precios de los SMS Premium (que se redujeron de 1,5 euros más IVA a 1,2 euros más IVA), por lo que la subida impositiva no supuso una variación significativa de precios. La subida del IVA de 2012 sí ha tenido una influencia negativa y especialmente nefasta en los STA ofrecidos parcial o totalmente a través de llamadas de valor añadido de código o prefijo 905, ya que el coste por llamada, que desde red móvil era de 1,95 euros hasta el 1 de septiembre de 2012, a partir de entonces se situó en los 2,00 euros, razón por la que ha desaparecido la técnica de marketing de los "precios psicológicos”, esa por la que se determinó el precio de cada llamada de código 905 en 1,65 euros más IVA hace ya tres años.

\subsection{Influencia económica}

El fenómeno de declive que analizamos no se explica únicamente por razones legales, sino que otros factores también tienen su afectación en el proceso decadente del negocio de las televisiones, consistente en la oferta de productos y servicios adquiribles vía SMS Premium o llamadas de valor añadido.

La crisis económica aparece como claro óbice a la buena dicha del negocio, un elemento de contexto económico auténticamente influyente en la decadencia del negocio, como reductor o depresor del consumo de este tipo de productos, por cuanto que es un hecho totalmente perturbador que provoca inevitablemente la constricción del gasto de las personas, reservado a los elementos más esenciales.

En el Hecho Relevante comunicado a la Comisión Nacional del Mercado de Valores (CNMV) correspondiente a los resultados de la empresa en el Primer Trimestre de 2012, Mediaset España explicita esta influencia al señalar que la partida de "Otros ingresos" (entre los que se incluyen los procedentes de STA) cayó un 32,5\%, hasta los 9,72 millones de euros, significando dicha caída de ingresos como el "reflejo de la situación de la economía española, que ha reducido el consumo en este tipo de productos"?

Datos obtenidos del Informe de Resultados de Mediaset España (Enero - Marzo 2012) http://www.mediaset.es/inversores/es/Informe- 
Una idéntica atribución o referencia al contexto económico como explicación de la caída de ingresos se produce en el Hecho Relevante comunicado a la CNMV correspondiente a los resultados de los nueve primeros meses del año 2012, como vimos antes, expresando allí que los "Otros ingresos" "se sitúan en 34,90 millones de euros", una cifra muy inferior a la registrada en el mismo período de 2011, cuando obtuvo 43,79 millones de euros y que explica de la misma manera (principalmente consecuencia de la caída de ingresos procedentes de SMS y teléfono) ${ }^{8}$.

\subsection{Influencia tecnológica}

Otro factor a tener en cuenta es el tecnológico, siendo que la aparición de nuevas tecnologías ha perjudicado el negocio de algunos servicios del negocio telefónico, lo que resulta sumamente chocante si tenemos en cuenta que una década antes fueron los paulatinos avances tecnológicos lo que causaron los sucesivos big bangs que ha experimentado el negocio de los Servicios de Tarificación Adicional, aumentando en número y mejorando en calidad estos.

Así, por ejemplo, tras la completa implementación de la red telefónica de datos 3G, se ha ocasionado un aumento en la oferta de tarifas planas de internet en el móvil por parte de los operadores de telefonía y, en consecuencia, un auge en las contrataciones de dicho servicio por parte de los usuarios, sustituyéndose el consumo de contenidos a través de STA por el que proporciona dicho servicio en el móvil (el mejor ejemplo en este sentido lo encontramos en el hecho de que ya no se descargan "politonos", previo envío de un SMS Premium, sino que se reproducen las canciones originales a través del propio reproductor de música de nuestro móvil). En relación con ese aumento de accesos a Internet desde el móvil hay que referir también el uso creciente de redes sociales por parte de los usuarios, moda a la que se han sumado también los medios, pese a que su gratuidad no les reporta los ingresos que obtenían de los famosos SMS-Opinión de los distintos programas de televisión (el espectador de televisión ya no envía SMS-Opinión desde su teléfono móvil -como sí hacía antes- ya que la televisión ahora le da la oportunidad de comentar el programa a través de Twitter, presentándose en la esquina superior izquierda de la pantalla televisiva una nueva "mosca", que explicita el hashtag a través del cual el espectador puede comentar, en dicha red social, el concreto contenido televisivo que se está difundiendo).

La afectación de la tecnología como condicionante de negocio es comentada en el libro "Mobile MK: La revolución multimedia", en el epígrafe "Los límites actuales de la eficacia del mobile marketing”, uno de los mejores sustentos teóricos de esta investigación. La antigüedad del libro, (fue publicado en 2005), resulta muy interesante, puesto que la importancia de la tecnología es proclamada allí en un sentido contrario al expresado:

resultados_MDSFIL20120508_0001.pdf, correspondiente al primer Trimestre de 2012 (Dirección web de información a accionistas de Mediaset España).

8 Datos obtenidos del Informe de Resultados de Mediaset España (Enero - Septiembre 2012) http://www.mediaset.es/inversores/es/SPANISH-CNMV_MDSFIL20121024_0002.pdf, correspondiente a los nueve primeros meses de 2012 (Dirección web de información a accionistas de Mediaset España). 
«El medio es muy bueno, especialmente ofrece gran potencial, pero hoy en día sólo estamos en sus comienzos. En primer lugar, actualmente estamos hablando de terminales con pantallas limitadas, muchos de ellos aún en blanco y negro (...) Muy posiblemente poco a poco va a ser una herramienta más potente con el incremento de la penetración de los terminales en color, el mayor uso de los mensajes multimedia, la recepción y descarga de vídeos, la posibilidad de ver la TV en el móvil con la tecnología 3G, etc. (...) También existen limitaciones técnicas por parte de los propios operadores para poder, por ejemplo, ver la TV simultáneamente en el móvil miles de personas, o para que se puedan enviar multitud de MMS superiores a 90k simultáneamente por falta de ancho de banda» (Román et al., 2005).

\subsection{Influencia de la percepción social}

No podemos dejar de declarar en este texto como un elemento de gran perturbación del negocio de los Servicios de Tarificación Adicional a través de SMS Premium y Llamadas de Valor Añadido la difusión por parte de los medios de comunicación de determinados pronunciamientos jurídicos o normativos, y otros de índole más informal, con relación al mismo. Aquello que genera grandes cantidades de capital se convierte en diana de muchas miradas, razón por la cual no es de extrañar que, con una frecuencia casi diaria, los medios de comunicación se hagan eco de las malas prácticas ocurridas en el existir del negocio de los Servicios de Tarificación Adicional. Ninguna anormalidad acaecida en el desarrollo de este negocio pasa desapercibida, sino todo lo contrario: cualquier irregularidad producida es publicitada con gran hincapié.

Así, el negocio telefónico se encuentra sometido a un juicio permanente por parte de los medios de comunicación, dándose a conocer todas las eventualidades que declaran la consumación de ilegalidades por parte de unos u otros intervinientes en el negocio, como la comunicación de sentencias judiciales, resoluciones institucionales, actuaciones de organismos o de particulares...

Esta realidad podría ser estudiada, incluso, a través de webgrafía exclusiva, ya que existen numerosos sitios dedicados por entero a analizar las oscuridades de este negocio, entre las que cabe destacar TenCuidado.es, que en su cabecera explica su razón de ser en los términos de que:

«TenCuidado es un proyecto independiente, que pretende alertar y dar a conocer las "rarezas" de los concursos 905, SMS y pseudo-sorteos, sin dejar de lado otras malas artes» (http://www.tencuidado.es)

También, EstafasTelefonicas.com, que describe su labor en el encabezado:

«Destapando las irregularidades de los concursos de televisión, radio, internet, prensa con SMS, 905, 902, 803, 806, alertas SMS...» (http://www.estafastelefonicas.com) 
La puesta en conocimiento del público de estos acontecimientos supone una absoluta destrucción del negocio, teniendo en cuenta que el resultado del mismo es determinado por aquel, como comprador (o no) de dichos servicios telefónicos, de acuerdo a su decisión de aceptación o de rechazo.

La persecución de las actuaciones de los responsables del canal Telesierra es, probablemente, uno de los acontecimientos judiciales que, publicitados por todos los medios, más ha deteriorado la imagen de los Servicios de Tarificación Adicional.

El diario El Mundo publicó en su edición del miércoles 2 de marzo de 2005 el artículo titulado "Detenidos los dueños de Telesierra acusados de estafar cinco millones de euros en concursos televisivos" ${ }^{\prime}$, donde confirmaba que fueron detenidos cuatro miembros de la familia Del Campo, propietaria de la televisión local Telesierra, acusados de estafar más de cinco millones de euros a través de concursos televisivos, para lo cual mantenía en conexión a los participantes durante 30 minutos.

En la noticia se da a conocer el origen de dicho proceso judicial, dato muy relevante de acuerdo a lo mencionado anteriormente, al nacer este de la denuncia de una organización de defensa de derechos de los consumidores, que es resultado de la gestión de las reclamaciones de aquellos:

«La operación, denominada Cadena, se inició tras las denuncias interpuestas por la Organización de Consumidores y Usuarios (OCU). Éstas, a su vez, tuvieron como detonante las numerosas reclamaciones efectuadas por los concursantes estafados» (El Mundo, 2 de marzo de 2005).

Dicho texto alerta al lector:

«La jefa de prensa de la OCU, Ileana Izverniceanu, destacó que la organización recibió más de un centenar de denuncias y muchas más consultas, pese a que a la gente le daba vergüenza reconocer que había sido víctima de una estafa (...) Izverniceanu afirmó que la "víctima tipo" de esta clase de prácticas era una persona mayor, que vive sola y que peca de ingenuidad ante la posibilidad de ganar un premio» (El Mundo, 2 de marzo de 2005).

Respecto al método de comisión de la estafa, en la noticia se explica que:

«Los programas concurso tenían una duración de una hora y media o dos horas y se emitían en directo y en diferido. Tras realizar una pregunta muy elemental (un refrán, una foto ligeramente distorsionada de un famoso), las llamadas eran retenidas durante un máximo de 30 minutos, el límite legal permitido para los teléfonos de tarificación adicional. Éstas eran atendidas por un contestador automático que informaba del coste y la duración

9 Datos obtenidos de http://www.elmundo.es/elmundo/2005/03/02/comunicacion/1109766198.html (Dirección web del diario El Mundo, que contiene el artículo "Detenidos los dueños de Telesierra acusados de estafar cinco millones de euros en concursos televisivos"). 
máxima, para después solicitar la respuesta, que supuestamente se grababa en una base de datos, y comunicaba que el usuario quedaba a la espera de entrar en concurso. A los treinta minutos la conexión se cortaba. Mientras, el presentador informaba de respuestas erróneas de supuestos concursantes. A punto de concluir el concurso, se daba entrada a una llamada con la respuesta acertada» (El Mundo, 2 de marzo de 2005).

Un efecto más nefasto en el negocio es presumible tras la aparición, años después, de noticias similares, como una acaecida en 2013, que de hecho no habla de detenciones por supuestos fraudes, sino de condenas firmes por estafas reales.

El diario $A B C$ ofreció todos los detalles de esta reciente decisión judicial en la noticia titulada "El Supremo confirma la condena de un año de cárcel contra la estrella del porno Torbe" ${ }^{10}$, donde explica:

«El Tribunal Supremo ha confirmado la sentencia dictada en febrero de 2012 por la Audiencia de Madrid que condenó a un año de cárcel a Ignacio A.F., conocido como “Torbe”, y a Paula S.G. por estafar a los telespectadores de una cadena de televisión privada a través de las llamadas telefónicas al programa "La hora de oro", que se emitía en 2006. En la sentencia, a la que tuvo acceso Europa Press, el Alto Tribunal desestima el recurso de casación interpuesto por Paula S.G. contra la citada resolución. Los magistrados de la Audiencia consideran a "Torbe" y a la otra acusada autores de un delito continuado de estafa, con la atenuante de dilaciones indebidas. Según la resolución, que ratifica la condena de un año, los acusados orquestaron un método para la obtención de una ganancia ilícita en el programa de televisión denominado «La hora de Oro»" ( $A B C$, 9 de febrero de 2013).

Seguidamente, se realiza una excelsa descripción que nos descubre el perfeccionamiento del método de estafa de uno y otro:

«En dicho programa, los telespectadores tenían que acertar una serie de respuestas que figuraban en la pantalla, debiendo llamar a un número de teléfono para poder cobrar el premio (...) A los telespectadores que llamaban a ese número de teléfono para consignar las respuestas acertadas, se les exigía, mediante una locución grabada, llamar a otro número para obtener el premio. Este segundo teléfono pertenecía a la sociedad mercantil Ekeace, cuyo representante legal es Ignacio A. F. Una vez las víctimas de la estafa llamaban a ese segundo teléfono, se les remitía a un tercero, también de tarificación adicional, con un precio en esta ocasión de 1,09 euros por minuto y cuya gestión y cobro de beneficios corresponde a la entidad Grande Amigos S. L., cuya representante legal es Paola S. G. Una vez realizaban la tercera llamada, las víctimas eran atendidas por personas físicas cuyas identidades se desconocen y cuyo objetivo era hacer creer a los participantes del concurso que efectivamente habían ganado un premio y que se lo estaban gestionando. Según el fallo, los espectadores que creían haber acertado las preguntas eran atendidos por diferentes personas, quienes trataban de prolongar al máximo la duración de la llamada» ( $A B C, 9$ de febrero de 2013).

10 Datos obtenidos de http://www.abc.es/tv/20130209/abci-supremo-condena-torbe-estafa-201302092057.html (Dirección web del diario $\mathrm{ABC}$, que contiene el artículo "El Supremo confirma la condena de un año de cárcel contra la estrella del porno Torbe"). 
Idéntico efecto se produce cuando estos mismos instrumentos de información dan a conocer casos particulares de víctimas de estafas por el uso de Servicios de Tarificación Adicional. Esta presentación de casos particulares de estafados se asocia habitualmente al concepto de sobretarificación, exponiéndose que tales personas han recibido facturas por importes no ajustados a la realidad del uso telefónico realizado.

Estas informaciones suponen un potencial freno generalizado a la compra de Servicios de Tarificación Adicional, especialmente cuando presentan las resoluciones sancionadoras que dan la razón de la víctima, como ocurre en el caso de la noticia publicada en la edición del diario El País titulada "La condena a un teleconcurso saca a la luz los abusos del 905"11. El texto explica que:

«Óscar C. (...) se quedó atónito cuando vio su factura de teléfono de octubre de 2006. Era unos 300 euros más alta de lo habitual. ¿El motivo? 218 llamadas a un teléfono que comenzaba por 905. Las había realizado, según su compañía de teléfono, a un concurso de televisión nocturno, Buenas Noches y Buena Suerte, realizado por la productora Portal Mix y emitido en Antena 3. Él aseguraba que nunca concursó. Por eso se fue a la Agencia Catalana de Consumo (ACC) e interpuso una reclamación. Cuatro años después, con una resolución de este organismo y una sentencia de lo contencioso-administrativo a su favor, Portal Mix debe devolverle 308 euros. El organismo catalán de consumo, dependiente de la Generalitat, aprovecha además y le impone a la productora una multa de 14.500 euros. A raíz de la denuncia, estudió las bases de los concursos que la productora elaboraba para Antena 3 y Telecinco y vio cláusulas abusivas (...) Al margen de las multas, lo pionero de la resolución contra la productora, señalan varias asociaciones de consumidores, es el motivo por el que la empresa debe devolver el dinero: no ha sido capaz de demostrar que el ciudadano de Cerdanyola hiciera esas llamadas (...) Los intereses del consumidor han prevalecido. "Hemos ido contra la empresa, y no contra la compañía de teléfono que hizo la factura, porque creemos que es la productora la que se lucra con este sistema de llamadas. Y si hay dudas sobre cómo lo ha conseguido, no es el consumidor quien debe demostrar que es inocente, sino la empresa que se lucra» (El País, 5 de noviembre de 2010).

Asimismo, la noticia recoge la opinión del portavoz de la asociación de consumidores FACUA, Rubén Sánchez, quien descubre que existen muchas denuncias por sobretarificación:

«Nosotros tenemos registrados más de 2.500 casos que denuncian que no hicieron llamadas masivas. Van desde personas que hicieron supuestamente 10 hasta el caso de un consumidor cuya factura indica que hizo 20.000 llamadas a uno de estos 905» (El País, 5 de noviembre de 2010).

Sin embargo, la resolución del caso dota al mismo de gran singularidad:

11 Datos obtenidos de http://elpais.com/diario/2010/11/05/sociedad/1288911603_850215.html (Dirección web del diario El País, que contiene el artículo “La condena a un teleconcurso saca a la luz los abusos del 905”).

70 | n 17, pp. 57-77 | doxa.comunicación 
«Es la primera vez, que sepamos, que en esta situación a quien se obliga a demostrar las llamadas es a la productora. Normalmente, se le pide al consumidor. Y como no puede demostrar que no las hiciera, acaba teniendo que pagar» (El País, 5 de noviembre de 2010).

A este respecto, es importante indicar que FACUA puede considerarse la organización defensora de los derechos de los consumidores y usuarios que, con mayor potencia, ha denunciado públicamente la facturación masiva de llamadas a líneas 905 no realizadas por los usuarios, creando incluso una web para recoger los casos de afectados: FACUA.ORG/905. Estas denuncias de quienes reclaman haber sufrido una "sobretarificación" (por contemplarse o consignarse en su factura telefónica consumos de tarificación adicional no efectuados) representan una durísima estocada contra el negocio telefónico.

Numerosas han sido también las denuncias públicas realizadas por particulares por sobretarificación en relación a Servicios de Tarificación Adicional prestados mediante el envío de SMS Premium. El año 2009 fue importante en ese sentido, por la profusión de noticias de afectados por sobretarificación en servicios de SMS Premium. Un alto porcentaje de ellas estuvieron relacionadas con el programa de televisión "Rico al Instante". Así, por ejemplo, DiarioVasco.com publicó "Me reclaman 5.000 euros por participar en un concurso de la tele", donde se cuenta la experiencia de María Cristina McArthy Cooper.

Este abuso también ha sido perpetrado por empresas dedicadas a ofrecer otros Servicios de Tarificación Adicional, y de ello también han alertado las asociaciones de defensa de los consumidores y usuarios, publicándose noticias en este sentido de manera reiterada. Así, en relación con los servicios telefónicos que constituyen contenidos de personalización del terminal telefónico del usuario (imágenes, sonidos, música, vídeos y videojuegos, etc.), igualmente ha sido muy insistente la denuncia por exceso de tarificación.

Por un lado, hasta 2009 fue frecuentemente denunciada la exigencia de envío por parte del usuario de un excesivo número de mensajes para recibir un determinado contenido de personalización del teléfono móvil, fecha en la que, con la entrada en vigor del Código de Conducta de los SMS Premium, estas actuaciones pasaron a estar vetadas, de acuerdo al punto 6.1.1.9. de dicho texto, que prohíbe expresamente «exigir el envío de dos o más mensajes sujetos a tarificación adicional para la compleción de un determinado servicio».

Por otro lado (y en este caso todavía hoy), son numerosas las acusaciones de fraude intrínseco en los denominados "servicios de suscripción", en los que el usuario es tarificado por los mensajes recibidos, increpándose (especialmente hasta 2009, cuando la reglamentación obligacional de dichos servicios fue regulada a través del citado Código de Conducta de los SMS Premium) que el usuario no es notificado suficientemente de las condiciones más relevantes que para él tiene dicho servicio (fundamentalmente, el carácter contractual y no de demanda de dichos servicios y el importe máximo mensual de ellos). 
Otro hecho noticiado habitualmente en los medios de comunicación que perjudica el negocio de los Servicios de Tarificación Adicional es el que hace constar el bloqueo de numeraciones de tarificación adicional a las entidades propietarias de las mismas, independientemente del incumplimiento que provoca dicha consecuencia, porque sitúa al espectador de televisión en una posición de mayor precaución.

La cancelación de numeración de tarificación adicional corresponde a la Comisión del Mercado de las Telecomunicaciones, por orden de la Comisión de Supervisión de los Servicios de Tarificación Adicional (CSSTA), lo que explica que la principal fuente de este tipo de noticias sea el blog de la Comisión del Mercado de las Telecomunicaciones (http://blogcmt.com/2012/11/13/sms-premium-cancelados).

Otra causa por la que se ha creado una idea negativa del negocio de los Servicios de Tarificación Adicional es la difusión de informaciones que apuntan a la comisión de irregularidades de tipo fiscal, lo que aparece como altamente chocante especialmente teniendo en cuenta que hablamos de una actividad que genera abundantísimos ingresos.

Un planteamiento originador de dudas a la legitimidad de los ingresos para la televisión pública procedentes del negocio telefónico se produjo a mediados del año pasado, a raíz de una sentencia del Tribunal Supremo, de la que lógicamente se hizo eco la agencia de noticias Europa Press:

Bajo el título "El Supremo confirma una sentencia que condenó a RTVE a pagar 9 millones de euros a Hacienda por juegos de azar"12, en ella se explica:

«El Tribunal Supremo ha desestimado un recurso de casación presentado por RTVE contra una sentencia (...) que condenó a la corporación a pagar 9 millones de euros al Ministerio de Hacienda en concepto de impuestos a juegos de azar dejados de abonar entre 2001 y 2002. El origen del conflicto se remonta a enero de 2001, cuando el Ente Público RTVE comenzó a organizar concursos realizados en diversos programas televisivos, en los que participaban los telespectadores de tales programas mediante el envío de mensajes SMS, llamadas telefónicas o, incluso, a través de correo electrónico. Tras comprobar los concursos realizados entre el periodo 2001 y 2007, la Inspección de Hacienda del Estado consideró que el Ente Público (...) no había satisfecho las correspondientes tasas (...) Como consecuencia de lo anterior, dicha Inspección de Hacienda practicó al Ente Público diversas liquidaciones tributarias correspondientes a los periodos que van desde 2001 hasta septiembre de 2007 por un importe conjunto de 12,9 millones de euros» (EuropaPress.es, 6 de noviembre de 2012).

La noticia especifica el razonamiento de la sentencia, que desestima definitivamente las pretensiones de RTVE, fundamentando su defensa en "echar balones fuera":

12 Datos obtenidos de http://www.europapress.es/nacional/noticia-supremo-confirma-sentencia-condeno-rtve-pagar-millones-euroshacienda-juegos-azar-20121106191848.html (Dirección web de la agencia de noticias Europa Press, que contiene el artículo "El Supremo confirma una sentencia que condenó a RTVE a pagar 9 millones de euros a Hacienda por juegos de azar"). 
«RTVE alegó que los juegos y concursos realizados deberían tributar según la tasa de juegos de combinaciones aleatorias y no por el de rifas, así como que el ente no fue el organizador de la rifa, ya que contrató ese servicio a terceros (...) No obstante, el Tribunal Supremo ha rechazado todas estas alegaciones, ya que, aunque el Ente Público contrató los servicios telefónicos y SMS necesarios para la realización de los sorteos, también era el que podía suspender la realización de los programas y también quien expidió las facturas para percibir el importe de la recaudación, y proceder, posteriormente, al reparto en la forma convenida» (EuropaPress.es, 6 de noviembre de 2012).

Otras veces, la mala fama de los Servicios de Tarificación Adicional no ha sido propiciada por la aparición de documentos oficiales de organismos e instituciones, sino a raíz de comentarios informales en foros y chats de Internet, algo que, por ejemplo, ocurrió (no sobre una cuestión tarifaria sino en relación con los intentos de evitar la entrega de los premios de dichos juegos a sus ganadores por parte de sus organizadores) en mayo de 2009, cuando en el Call TV“La noche millonaria”, producido por Llama Televisión y emitido en el extinto canal de TDT Hogar 10, dicha productora pretendió negar un premio de 12.000 euros a un concursante que superó la prueba planteada para optar a ganar el premio especial del programa (habiendo acertado los tres números contenidos en un sobre), pues ello provocó un verdadero revuelo en determinadas webs de este tipo, de lo que se hicieron eco después, lógicamente, muchos medios de comunicación.

Mayor significación tuvo la reacción de algunos foros y chats cuando, en diciembre de 2009, “Gana Ahora”, Call TV producido también por Llama Televisión y emitido en La Sexta, quiso negar un premio de 60.000 euros a un concursante que superó la prueba planteada para optar a ganar el premio especial del programa (al adivinar las cuatro letras contenidas en un sobre), hecho que se visibilizó luego en los medios de comunicación oficiales de una manera aún más poderosa que con el suceso de mayo de 2009, provocándose la burla hacia el formato, incluso por parte de programas de la propia cadena de televisión emisora del espacio en el que sucedió lo expresado (como "Sé lo que Hicisteis", de La Sexta).

Estas y otras prácticas de "ahorro de costes" también han sido denunciadas a través de fórmulas todavía más ingeniosas, como mediante la subida de vídeos en páginas web de alojamiento de contenidos audiovisuales (como YouTube o Dailymotion) o con la creación de blogs en páginas web que ofrecen dicho servicio de manera gratuita (como el servidor de blogs Blogspot) por parte del propio usuario que se considera estafado.

Así, por ejemplo, un usuario cuelga en YouTube un vídeo con el título "El presunto fraude de MEDIAGENERIS, la TELESIERRA del año 2010, en Telecinco y MarcaTV”"13, en cuyo apartado de Información explica que se puede apreciar el presunto fraude que comete la productora Mediageneris en los concursos que produce.

13 http://www.youtube.com/watch?v=cBHSJs-40ME. 
Como conclusión, dicho usuario concluye que todo ello «son pequeños ejemplos del fraude que comete esta empresa, la nueva Telesierra de hoy en día: falsos ganadores, falsas respuestas... que sin lugar a dudas constituyen una verdadera estafa para todo aquel que de manera inocente, piensa que puede ganar dinero llamando al 905 que aparece en pantalla».

Todo esto ha provocado una asimilación colectiva de los Call TV como "programas estafa" llenos de pequeños fraudes (una idea aplicable, en general, a cualquier juego cuyo acceso se produce mediante el envío de mensajes y la realización de llamadas de teléfono) y, por ello, su extinción aparece como la consecuencia lógica. A esta realidad se refieren Mónica Beneyto, Balma Badal y Marta Puigferrer, autoras del artículo "El negocio multimillonario de los concursos de televisión y sus pequeñas trampas" ${ }^{14}$.

En este sentido, también es importante señalar que las redes sociales han sido alojamiento principal de las más informales quejas hacia los excesos producidos en la oferta de servicios de suscripción. Un ejemplo de ello es el grupo en Facebook de "Afectados por Buongiorno Myalert S.A." ${ }^{15}$.

\section{Conclusiones}

El declive del negocio de los Servicios de Tarificación Adicional en las cadenas de televisión españolas se explica por causas o razones de distinta orden: legales, económicas y de recepción.

Así, aunque el ánimo de lucro mediante esta fórmula recaudatoria telefónica persiste, dichas acciones ya no reportan los resultados de hace unos años, debido a las consecuencias de la regulación del sector, así como por la desaceleración económica que atraviesa nuestro país y el avance tecnológico, que provoca la obsolescencia de algunos de los productos y servicios telefónicos altamente exitosos en favor de otras nuevas posibilidades.

Los medios de comunicación, formales e informales, también tienen mucho que ver en dicho descenso, pero no con responsabilidad directa, sino por el efecto lógico que provoca en el usuario la difusión de noticias exponiendo irregularidades acaecidas en el desarrollo del negocio.

Cabe esperar, en el futuro más inmediato, que se produzca todavía un mayor descenso en el consumo de estos servicios, por la contracción del gasto que resulta de la realidad de austeridad económica que atraviesa nuestro país. Ciertamente, debido a la importancia de estos factores externos, resulta muy difícil pronosticar la realidad en un plazo mayor de tiempo, si bien parece evidente que, en un contexto de prosperidad económica favorecedor del gasto, la facilidad de uso de los Ser-

14 http://tencuidado.es/con-concursos-905/calltv-al-limite-de-la-legalidad.

15 http://www.facebook.com/group.php?gid=129607013721132 
vicios de Tarificación Adicional (accesibles con un simple gesto que puede realizarse desde casi cualquier lugar) será la gran aliada para propiciar la reversión de esta evolución negativa.

Ante este paisaje de muchas dudas y pocas certezas, la atención a los planteamientos de los mayores profesionales de este sector resulta fundamental. En este sentido, inicialmente podría parecer que la confesión de Chema Bautista, Director de Nuevos Negocios de Mediaset España, quien define la función económica del negocio en los últimos años como algo muy relativo, en el sentido de que «su volumen si bien es importante no compensa la caída del mercado publicitario», nos crea dudas acerca de cuál será el destino del negocio telefónico para cada una de las posibles evoluciones de la realidad económica, e implicando por tanto una variación de la situación actual.

Esa crisis económica, sin embargo, ha desvelado que los profesionales encargados de la gestión de las empresas televisivas no han concentrado todas sus fuerzas en alcanzar la solución al problema fundamental de sus economías (que es, lógicamente, el descenso de la inversión publicitaria), lo que habría implicado el abandono de actividades con una importancia menor, como es el negocio telefónico, sino que todo lo contrario: la función económica de las demás actividades comerciales de la empresa televisiva ha sido apreciada más que nunca y, en consecuencia, el negocio sigue presente incluso cuando los números en los que se expresa dicha función se han reducido de manera preocupante (esto es, cuando los espectadores de televisión, aquejados también por esa misma crisis económica, han pisado el freno al consumo de dichos servicios telefónicos).

En todo caso, reconociendo el mismo Chema Bautista que los Servicios de Tarificación Adicional «siempre se han considerado una actividad comercial», es fácil imaginar e incluso dilucidar cuáles son las otras piezas que completan el puzle, cuáles son los factores con los que se puede discernir su devenir: la existencia de una lógica económica para el empresario de televisión (como negocio) y de otra experiencial para el espectador de dicho medio (como ocio). La aquiescencia de ambos son, por ende, los dos requisitos ineludibles.

\section{Referencias bibliográficas}

$A B C$ (2013): "El Supremo condena la condena de un año contra la estrella del porno «Torbe»", $A B C$, 09-II-2013. Disponible en: http://www.abc.es/tv/20130209/abci-supremo-condena-torbe-estafa-201302092057.html [Consultado: 10/05/2013]

Delgado, C.; Gómez, R. G. (2010): “La condena a un teleconcurso saca a la luz los abusos del 905”, El País, 05-XI-2010. Disponible en: http://elpais.com/diario/2010/11/05/sociedad/1288911603_850215.html [Consultado: 10/05/2013]

Diario Vasco (M.J.T.) (2009): “Me reclaman 5.000 euros por participar en un concurso de la tele”, Diario Vasco, 17-IV-2009. Disponible en: http://www.diariovasco.com/20090417/al-dia-sociedad/reclaman-euros-participar-concurso-20090417.html [Consultado: 10/01/2013] 
Europa Press (2012): "El Supremo confirma una sentencia que condenó a RTVE a pagar 9 millones de euros a Hacienda por juegos de azar", Europa Press, 06-XI-2012. Disponible en: http://www.europapress.es/nacional/noticia-supremoconfirma-sentencia-condeno-rtve-pagar-millones-euros-hacienda-juegos-azar-20121106191848.html [Consultado: $10 / 01 / 2013]$

Ramírez, Pedro J. (2005): "Detenidos los dueños de Telesierra acusados de estafar cinco millones de euros en concursos televisivos", El Mundo, 02-III-2005. Disponible en: http://www.elmundo.es/elmundo/2005/03/02/comunicacion/ 1109766198.htm [Consultado: 10/01/2013]

Román, F; González, F; Marinas, I. (2005): Mobile MK. La revolución multimedia. Madrid: ESIC Editorial.

\section{Textos legales}

Código de Conducta de 29 de junio de 2009, para la prestación de los STA basados en el envío de mensajes SMS Premium. Ley 13/2011, de 27 de mayo, de Regulación del Juego.

Ley 7/2010, de 31 de marzo, General de la Comunicación Audiovisual.

Ley 8/2009, de 28 de agosto, de financiación de la Corporación de Radio y Televisión Española.

Orden EHA/3083/2011, de 8 de noviembre, por la que se aprueba la reglamentación básica de los concursos.

Resolución de 8 de julio de 2009, que modifica el Código de Conducta para la prestación de los STA de fecha 23 de julio de 2004.

Resolución 4 de diciembre de 2008, de la Secretaría de Estado de Telecomunicaciones y para la Sociedad de la Información, por la que se atribuye el código telefónico 905 a la prestación de servicios de tarificación adicional.

\section{Sitios web}

http://blogcmt.com/2012/11/13/sms-premium-cancelados [Consultado: 10/05/2013]

http://www.estafastelefonicas.com [Consultado: 10/05/2013]

http://www.facebook.com/group.php?gid=129607013721132 [Consultado: 10/05/2013]

http://www.facebook.com/group.php?gid=129607013721132 [Consultado: 10/05/2013]

http://facua.org/905 [Consultado: 10/05/2013]

https://www.facua.org/es/noticia.php?Id=2676 [Consultado: 10/05/2013]

http://www.infoadex.es/Resumen_Estudio_Inversiones_InfoAdex_2012.pdf [Consultado: 10/05/2013]

http://informecmt.cmt.es [Consultado: 10/05/2013]

http://www.mediaset.es/inversores/es/Informe_MDSFIL20111227_0031.pdf [Consultado: 10/05/2013] 
http://www.mediaset.es/inversores/es/Informe-resultados_MDSFIL20120508_0001.pdf [Consultado: 10/05/2013] http://www.mediaset.es/inversores/es/SPANISH-CNMV_MDSFIL20121024_0002.pdf [Consultado: 10/05/2013]

http://www.periodistadigital.com/periodismo/tv/2012/04/12/empresa-producira-programa-julia-otero-esta-senaladahacienda-mediagroup-eurostar.shtml [Consultado: 10/05/2013]

http://www.tencuidado.es [Consultado: 10/05/2013]

http://www.youtube.com/watch?v=cBHSJs-40ME [Consultado: 10/05/2013] 